\title{
Higher Incidence of Small Y Chromosome in Humans with Trisomy 21 (Down Syndrome)
}

\author{
R. S. VERMA, ${ }^{(28)}$ A. HUQ, C. MADAHAR, Q. QAZI, AND H. DOSIK \\ Departments of Laboratories and Medicine, The Jewish Hospital and Medical Center of Brooklyn, Departments of \\ Medicine and Pediatrics-State University of New York Downstate Medical Center, Brooklyn, New York, USA
}

\begin{abstract}
Summary
The length of the $Y$ chromosome was measured in 42 black patients with trisomy $21(47, X Y,+21)$ and a similar number of normal individuals of American black ancestry. The length of the $Y$ was expressed as a function of $Y / F$ ratio and arbitrarily classified into five groups using subjectively defined criteria as follows: very small, small, average, large, and very large. Thirty-eight $\%$ of the trisomy 21 patients had small or very small Ys compared to $2.38 \%$ of the controls $(P<0.01)$. In both populations the size of the $Y$ was not normally distributed. In the normals it was skewed to the left, whereas in the Downs the distribution was flat (platykurtic). A significantly higher incidence of $Y$ length heteromorphisms was noted in the Down as compared to the normal black population. In the light of our current understanding that about one-third of all trisomy 21 patients are due to paternal nondisjunction, it may be tempting to speculate that males with small $Y$ are at an increased risk for nondisjunction of the 21 chromosome.
\end{abstract}

\section{Speculation}

The present study suggests that one-third of trisomy 21 cases have small Y chromosome. Presently, it is believed that approximately one-third of all cases of Down Syndrome are due to "paternal" nondisjunction. Therefore, it is speculated that fathers with small $Y$ chromosome might be at higher risk for nondisjunction for chromosome 21.

The heteromorphisms in length of the long arm of the human $\mathrm{Y}$ chromosome of individuals and of ethnic groups is a long established fact $(7-10)$, and its inheritance at constant length is well documented $(2,5,14,15)$. Lubs and Patil (23) suggest that there exists a north/south gradient for the length of the $Y$ in Europeans; men of Mediterranean origin having a longer $Y$. The biologic and clinical significance of human $Y$ chromosome heteromorphisms, however, are poorly understood (12). Although a longer $Y$ has been reported in criminals (22), no length differences were observed between criminals and noncriminal controls in several other studies $(1,3,4,6,16,17)$. Consequently, no consistent relation between the length of the $Y$ and behavior has been found. A longer $Y$ has also been implicated as an important cause of fetal loss $(11,18,19)$. Our report concerns the differences in the length of the $\mathrm{Y}$ chromosome (as a function of the $\mathrm{Y} / \mathrm{F}$ index) in 42 American blacks with trisomy $21(47, X Y,+21)$ and that of 42 normal individuals of similar racial background, in order to comment on possible clinical significance.

\section{MATERIALS AND METHODS}

For this investigation we selected 42 black Americans who were referred for cytogenetic diagnosis and were found to have trisomy $21(47, X Y,+21)$. Their ages ranged from newborn to 16 years old. Forty-two control individuals of similar racial backgrounds were also included. The controls had negative medical histories and were unrelated. Lymphocyte metaphases were obtained by a modification of the Moorhead technique (24). At least five to ten GTG (G-bands by Trypsin using Giemsa) (20) banded metaphases were photographed from each specimen on high contrast copy film using a Zeiss photomicroscope III.

The four best banded cells were selected from each individual. Chromosomes 19, 20 and $\mathrm{Y}$ were directly measured from the negative by projecting the film using a Simmons Omega point light source enlarger (Simmons Omega Inc., N.Y., U.S.A.). The value of " $F$ " was determined as the average length of the four $F$ group chromosomes and the $\mathrm{Y} / \mathrm{F}$ ratio was calculated for each cell. The final $\mathrm{Y} / \mathrm{F}$ ratio for the individual was expressed as the average of four cells. A test of significance ( $t$ test) was performed to examine the differences in the two populations (21).

Table 1. Classification and frequencies of $Y / F$ indices from 42 down and 42 normal black americans

\begin{tabular}{|c|c|c|c|}
\hline \multirow{2}{*}{$\begin{array}{l}\text { Class intervals } \\
(\mathrm{Y} / \mathrm{F} \text { index })\end{array}$} & \multirow[b]{2}{*}{ Sizes } & \multicolumn{2}{|c|}{ Frequencies } \\
\hline & & $\begin{array}{c}\text { Normal } \\
n(\%)\end{array}$ & $\begin{array}{c}\text { Downs } \\
n(\%)\end{array}$ \\
\hline$\leq 0.80$ & Very small & $0(0.00 \%)$ & $2(4.76 \%)$ \\
\hline $0.81-0.94$ & Small & $1(2.38 \%)$ & $14(33.33 \%)$ \\
\hline $0.95-1.09$ & Average & $27(64.28 \%)$ & $17(40.47 \%)$ \\
\hline $1.10-1.23$ & Large & $13(30.95 \%)$ & $9(21.42 \%)$ \\
\hline$>1.23$ & Very large & $1(2.38 \%)$ & $0(0.0 \%)$ \\
\hline$\%$ Heteromorphism ${ }^{1}$ & & $35.72 \%$ & $59.53 \%$ \\
\hline
\end{tabular}

${ }^{1}$ See text for explanation.

\section{RESULTS AND DISCUSSION}

The average length of the $Y$ in controls and trisomy 21 patients were 1.09 and 0.97 , respectively; however, the length distribution in the controls was skewed to the left whereas in the patients it was platykurtic. Hence, to compare the average length of the $Y$ chromosome of one group to another was considered inappropriate.

The length of the human $Y$ chromosome is arbitrarily classified into five groups designated as: very small, small, average, large, and very large. The logic behind this classification has been described elsewhere (25). The frequency distribution of the $Y / F$ index in patients with trisomy 21 is compared with that of normal controls in Table 1. A significantly higher incidence of small and very small $\mathrm{Y}$ was found in the patients as compared to controls (38.09\% versus $2.38 \%)(P<0.01)$.

In order to calculate the frequency of heteromorphisms, the most frequent class may be considered as so-called "normal." On the basis of this assumption, it can be concluded that the frequencies of length heteromorphisms of the $\mathrm{Y}$ chromosome in Downs and normals was $59.53 \%$ and $35.72 \%$ respectively, which is significantly different $(P<0.01)$, i.e., a higher incidence of length heteromorphisms of the $\mathrm{Y}$ chromosome was noted among Downs in comparison to normal controls. 
The causes for nondisjunction in meiosis in humans remains largely unknown. The current studies of families with Down syndrome suggest that about one-third of all cases of trisomy 21 are due to paternal nondisjunction $(13,26)$. In the present study, a higher proportion of trisomy 21 patients $(P<0.01)$ had a small or very small $\mathrm{Y}$ chromosome in comparison to the controls. Because the $Y$ chromosome is inherited at constant length from the father to his male offspring, a significantly higher proportion of fathers of our patients were carriers of the small Y chromosome. It is tempting to surmise that males with a small $\mathrm{Y}$ are at a higher risk for nondisjunction. A similar study of the $\mathrm{Y}$ size in aneuploidies where paternal nondisjunction was established may be helpful in answering this question.

\section{REFERENCES AND NOTES}

1. Akesson, H. O., and Wahlstrom, J.: The length of the $\mathrm{Y}$ chromosomes in men examined by forensic psychiatrists. Hum. Genet., 39: 1 (1977).

2. Beltran, I. C., Robertson, F. W., and Page, B. M.: Human Y chromosome variation in normal and abnormal babies and their fathers. Ann. Hum. Genet. 42: 315 (1979).

3. Benezech, M., Noel, B., and Mouget, A.: Longueur du chromosome Y, intelligence et comportement dans une population de medico-legaux. Hum. Genet. 41: 211 (1978).

4. Benezech, M., Noel, B., Travers, E., and Mottet, J.: Conduite antisociale et longeur du chromosome Y. Hum. Genet., 32: 77 (1976).

5. Bishop, A., Blank, C. E., and Hunter, H.: Heritable variation in the length of the Y chromosome. Lancet, 2: 18 (1962)

6. Brogger, A., Urdal, T., Larsen, F. B., and Lavik, N. J.: No evidence for a correlation between behavior and the size of the $\mathrm{Y}$ chromosome. Clin. Genet., 11: 349 (1977).

7. Charlesworth, B.: Model for evolution of $\mathrm{Y}$ chromosomes and dosage compensation. Proc. Natl. Acad. Sci., 75: 5618 (1966).

8. Cohen, M. M., Shaw, M. W., and MacCluer, J. W.: Racial differences in the length of the human Y chromosome. Cytogenetics, 5: 34 (1966).

9. Denver Conference: A proposed standard system of nomenclature of human mitotic chromosomes. Lancet, 1: 1063 (1960).

10. Frota-Pessoa, O., and Arantangy, L. R.: The degeneration of the Y chromosome. Rev. Bras. Pesq. Med. Biol., 1: 241 (1968).

11. Genest, P.: Chromosome variants and abnormalities detected in 51 married couples with repeated spontaneous abortions. Clin. Genet., 16: 387 (1979).

12. Lubs, H. A. and Patil, S. R.: Mediterranean origin of long $Y$ chromosomes in Caucasians. Am. J. Hum. Genet., 27: 60A (1975).

13. Magenis, R. E., and Chamberlin, J.: Parental origin of non-disjunction. In Trisomy 21 (Down syndrome): Research Prospective (ed) de la Cruz and Gerald. University Park Press, Baltimore, MD., (1981).

14. McKenzie, W. H., Hostetter, T. L., and Lubs, H. A.: Y Family Study: heritable variation in the length of the human Y chromosome. Am. J. Hum. Genet., 24: 686 (1972).

15. Monsalve, M. V., Erdtmann, B., Otto, P. A., and Frota-Pessoa, O.: The human Y chromosome: racial variation and evolution. Rev. Brasil. Genet., 4: 433 (1980).

16. Nielsen, J., and Friedrich, U.: Length of the Y chromosome in criminal males. Clin. Genet., 3: 281 (1972).

17. Nielsen, J., and Nordland, E.: Length of the $Y$ chromosome and activity in 2 boys. Clin. Genet., 8: 291 (1975).

18. Nielsen, $\mathrm{J}$.: Large $\mathrm{Y}$ chromosome $(\mathrm{Yq}+)$ and increased risk of abortion. Clin. Genet., 13: 415 (1978).

19. Patil, S. R. and Lubs, H. A.: A possible association of long $Y$ chromosomes and fetal loss. Hum. Genet., 35: 233 (1977).

20. Seabright, M.: A rapid banding technique for human chromosomes. Lancet, 2: 971 (1971).

21. Sokal, R. R. and Rohlf, F. J.: Biometry. The Principles and Practice of Statistics in Biological Research. W. H. Freeman, San Francisco.

22. Soudek, D. and Laraya, P.: Longer Y chromosome in criminals. Clin. Genet., 6: 225 (1974).

23. Verma, R. S. and Dosik, H.: Human chromosomal heteromorphisms: Nature and Clinical Significance. Int. Rev. Cyto., 62: 361 (1980).

24. Verma, R. S., Rubenstein, C., and Dosik, $\mathrm{H}$.: Effect of $\mathrm{CO}_{2}$ on short term human lymphocyte culture in vitro. IN VITRO, 13: 806 (1977)

25. Verma, R. S., Dosik, H., Scharf, T., and Lubs, H. A.: Length heteromorphisms of fluorescent (f) and non-fluorescent (nf) segments of human Y chromosome: Classification, frequencies and incidence in normal caucasians. J. Med. Genet., I5: 277 (1978).

26. Verma, R. S. and Dosik, H.: Trisomy 21 in a child due to paternal non-disjunction as determined by RFA technique. Jap. J. Hum. Genet., 23: 17 (1978).

27. The technical assistance of Ms. Hardeep Bhusri, Mr. Marvin Ehlin, and Mr. Jorge Rodriguez is gratefully acknowledged. We are indebted to all those who have generously donated their blood for this study.

28. Requests for reprints should be addressed to: Ram S. Verma, Ph.D., Chief, Division of Cytogenetics, The Jewish Hospital and Medical Center, 555 Prospect Place, Brooklyn, N.Y., 11238, U.S.A.

29. Received for publication November 2,1981

30. Accepted for publication March 4, 1981. 